\title{
Adaptation Strategies Through a New Identity: A Comparative Analysis of Two Generations of Chechen Migrants in Belgium
}

\author{
Lida Kurbanova ${ }^{1},{ }^{*}$ Hanifa Nalgieva ${ }^{2}$, Laila Ismailova ${ }^{3}$, Zara Umarova ${ }^{3}$ \\ ${ }^{1}$ Chechen State University named after A.A. Kadyrova, Department of Theory and Technology of Social Work, \\ Grozny, Russia \\ ${ }^{2}$ Chechen State Pedagogical University, Department of Primary Education Methodology, Grozny, Russia \\ ${ }^{3}$ Grozny State Oil Technical University named after L.D. Millionshchikova, Department of social and humanitarian \\ disciplines, Grozny, Russia \\ *Email: $\underline{\text { medna59@mail.ru }}$
}

\begin{abstract}
The study analyses the structure of the formation of identification strategies, social, cultural, religious attitudes of two generations of Chechen migrants: those who arrived in the country as adults and their children, who grew up in migration conditions.

The analysis is based on comparing the results of sociological studies conducted by the author in 2011 among Chechen migrants who came to Belgium in the 90s during two Chechen military companies and the results of studies conducted in 2019 among the second-generation Chechen migrants who grew up in Belgium.

The analysis made it possible to build a new paradigm of the process of adaptation of migrants of two generations due to the process of identity transformation. At the same time, it was revealed that the adaptation strategies of parents changed during the period of growing up of children from forced integration into someone else's social order due to the lack of a real alternative to the conscious adoption of basic life strategies in the country of residence. The adaptation of children who grew up in the migration conditions differs from the nature of the adaptation of parents. If the adaptation of parents was primarily limited to the level of acceptance/rejection of everyday practices and the temporary prospects of their and their children's residence in the country of migration, then adaptation as a process of the second generation of migrants affected deeper levels of identification characteristics.

The paper attempts to analyse the content of the discourse "new identity". This new identity model, which we are cautiously "groping" among second-generation Chechen migrants, can serve as a vital resource for adaptation in places of settlement. In some sociological studies, the respondents themselves designated this new model as "new Chechens".
\end{abstract}

Keywords: Sociology of migration, Identity, Two generations of migrants, Adaptation, Traditional values.

\section{INTRODUCTION}

Migration processes in the world today are a social landscape in which people of different social, cultural and religious attitudes are forced to engage in several interactions in places of settlement, where the identification strategies of the receiving and instilling parties undergo a process of mutual adaptation. In these conditions, the level of inclusion and activity of acceptance/rejection of the other side varies among different generations of migrants. A comparative analysis of the adaptation mechanisms of the generation who arrived in the country of settlement as adults and the second generation of children who grew up in migration conditions makes it possible to find out the trajectory of adaptation as a process in different generations of migrants. This will allow us to identify the potential dynamics of forming a new identification model of a Chechen migrant, which would serve as an additional resource for adaptation in the habitat. Based on these considerations, the goal was set: to make a comparative 
analysis of the identification strategies of two generations of Chechen migrants, through a comparison of sociocultural, religious, social and axiological attitudes of the older generation and youth, the following tasks were identified to achieve this goal:

1. Using the findings of a study among older migrants [1] and a survey in the form of in-depth interviews among young people (Belgium 2019), to identify coincidences/discrepancies in the value attitudes of young people who grew up in a European environment and their parents on several indicators: education, values (ethnic, cultural, religious, civil, legal) in the conditions of migration.

2. To identify the dominant value attitudes in two generations that contribute to becoming an adaptive resource in migration conditions.

3. To analyse the degree of influence of adaptation on the subjective well-being and psychological comfort of the migrant.

4. To consider the points of coincidence /discrepancy between the liberal and traditional values of two generations of migrants in the context of their relationships between age strata and ways and forms of legitimisation of the new identity model.

\section{RESEARCH METHODS}

\subsection{Empirical methods}

Qualitative survey (in-depth interviews) $(\mathrm{N}=24: 12$ boys, 12 girls; age: 17-23 years; interview time: from 1.5 to 4 hours; August 2019)).

According to the researchers, the fundamental thesis of our reasoning within the framework of the designated problem can serve, "one of the problems caused by the growth of the Muslim population in Europe is related to issues of identity and self-identification. And what is essential, this problem concerns both Europeans in general and European Muslims in particular [2]. When the number of Muslims migrating from different countries and for various reasons become permanent residents and citizens of EU countries [3], this identity needs to be rethought.

As a result of the sociological research, the author concludes that the fault of the indicators of the identification series takes place within the immigrant community, particularly between representatives of different generations. There are cases, even within the same family. Moreover, the search for identity may lie within a particular person.

It seems that the analysis of the designated parameters of the problem will make it possible to build a new paradigm of adaptation as a result of the transformation of the identity of both the older generation and the youth.
It will help to understand the structure, content and content of the new identity, which in its essence can also be a rethought identity discourse. In any case, a person who has managed to co-opt reality with two cultural dimensions in himself has a chance of constructive coexistence. This is a new model that we are cautiously "groping" among Chechen migrants. In some sociological studies, the respondents themselves designated this new model as "new Chechens".

\subsection{Theoretical framework of the study}

The theoretical and methodological prerequisites of this study are based on several methodological theses, the essence one of them is the idea that social interactions are the dominant factor in social reality, their basis is social identification with "our" groups and communities, on the one hand, "this is us, within ourselves", and on the other hand, relations with "not our own" or "alien" groups and communities. From this approach point of view, when studying self-identification, it is essential to pay attention to the existence of opposition of self-identities with some groups and communities, namely groups of "strangers", "not their own", with which the social interaction of a person who perceives himself as a "representative" of his group close to him takes place [3].

Another theoretical framework of the study is the basic thesis of social knowledge of the sociology classics P. Berger and T. Lukman consists of the fact that the formation of social identity is a rather complex process, which includes the sequential entry of an individual into the field of dialectics of subjective and objective realities [4].

Through the internalisation mechanism, social experience is created and accumulated [5]. At this stage, identity expresses not so much the process of relating oneself to others but the result of this correlation.

Identity, thus, helps the interacting people to find both points of contact, commonality and unity, to establish their common relationship to the unified field of values and norms, similar assessments in understanding things and experiences, and to understand the "demarcation line" that is embedded in the tolerant behaviour, in the mentality of both sides.

Thus, migration is inevitably accompanied by a transformation of self-identity. S. Bochner was one of the first who tried to identify and describe the consequences of migration for both group and individual identity [6].

The social adaptation of migrants is not only a sociogroup phenomenon. In particular, S. Bochner noted that migrants might have different acculturation strategies concerning different objects [7]. The researcher's recognition of the existence of several adaptation strategies in an individual with the status of a migrant finds understanding and theoretical generalisation in 
another work published in 2019 by the famous American social philosopher and political scientist Francis Fukuyama "Identity. The desire for recognition and the policy of rejection." The author argues that the problem of adaptation of people of different cultures often lies in the plane of different vector values of an individual and the possibility of his moral freedom. This freedom in the migrant's mind is a kind of construct of value formations: on the one hand, the maximally expanded interpretation of the freedom of the individual's inner world, framed by the democratic institutions of European states, on the one hand, on the other hand, freedom as awareness of the migrant's collective responsibility to the religious community-the Ummah, ethnic group and traditional morality. The philosopher concludes that modern liberal societies have inherited the moral confusion caused by the disappearance of common religious beliefs. Labelling citizens of European states as representatives of Christian culture would be a big generalisation. Their constitutions (of European countries) protect the dignity of the individual and the rights of the individual, and this dignity seems to be based on the ability of people to make moral choices [8]. But what is the breadth of such a choice? Is it limited to accepting or rejecting a set of ethical rules established by society, or does true independence also involve the ability to create these rules?

Based on the theoretical framework outlined, we tried to compare the adaptive resource of two generations of Chechen migrants who have been living in Belgium for 20 years. The study has led us to a new trajectory of understanding the concept of migrant identity, where the taxonomic levels of the discourse of ethnic identity are transformed in the direction of changing priorities. And what was conditionally essential and significant for parents becomes secondary or loses its relevance and significance in the scale of value priorities of young people born and raised in Europe or came there as young children.

\section{IDENTIFICATION STRATEGIES OF TWO GENERATIONS OF MIGRANTS}

\subsection{Religious and cultural identity}

A significant sign of self-identification of Chechen migrants is confessional affiliation ("we are people of our faith"). $65.0 \%$ of respondents in Belgium identified themselves on this basis (2011).

Almost all respondents are concerned about the loss of cultural identity as the basis of their ethnic identity. The research data makes it possible to understand the nature of the respondents' attitude to the present state and the prospect of preserving their ethno-culture in a nonethnic environment. Chechen migrants perceive and experience the severity of fears associated with maintaining their ethnocultural identity in different ways; actions aimed at mitigating the certainty of the impact of acculturation processes on individuals and their groups, primarily family ones, are arranged differently.

The data obtained indicate that a significant part of the respondents is sceptical about the possibilities and prospects of preserving the traditions of their people in conditions of permanent or relatively long-term residence in a foreign cultural environment. This is especially evident in the answers to the question: "Living in a different environment, are you afraid that you will lose your culture?): "I'm trying to save something, but the further away from my homeland, the more difficult it is." A relatively small part of the respondents, $5.3 \%$, accept and implement the assimilation strategy in their practices because they stressed that "They do not see much sense in their culture." The generalising narrative was as follows: traditions and customs are observed only as a tribute to antiquity, there is little practical sense in them, and there is a lot of hassle. Rituals are complicated and observing them is a big emotional burden. "It's more accessible here, and no one evaluates you for anything: where did you go, what are you wearing, I think all this will die off soon, why cling? If they hear such a judgment, they will condemn, they say, he betrayed the nation. But I think there is no need for all this."

The data analysis shows that respondents from Belgium treat the issue of compliance with foreign cultural influence in a gender-democratic way, distributing risks and responsibilities more evenly. I.e. men and women noted that both parents should be equally responsible for the child's socialisation in a multicultural environment, worried about preserving his cultural and religious identity. At the same time, according to our observations, women have a higher adaptive resource than men. Still, at the same time, in this survey, $25.0 \%$ of men and $35.9 \%$ of women surveyed here believe that "integration into another culture does not depend on gender."

Integration into a foreign society does not have specific content. Even in the most favourable variant, it does not remove its problems of developing migrants as an independent ethnic group. At the same time, it may not be necessary to maintain such independence. For a long time, the cultural potential brought by the migrant is sufficient for him. That is, migrants, especially for the first 5-10 years, do not see a particular need for close cultural contact with representatives of the titular ethnic group if they live in a large ethnic community. Social relationships with representatives of another culture and religion are functional and do not occupy a significant social time-space in the life of a migrant. In the conditions of local closed settlements and even individual families, the migrant is naturally reproduced in the upbringing and socialisation of children for an extended period and even several generations. Still, sooner or later, the ethnic group faces the problem of 
biculturalism. This is inevitable because adult children and grandchildren begin to determine its dynamics.

The materials of the sociological research provide an opportunity to establish to what extent the national language acts as a means of self-identification; it has also become entirely predictable that having lived for a relatively long time (10-20 years) in Belgium, Chechen migrants have not yet mastered the language adopted here in official communication and simple communicative terms. Only a third of respondents in Belgium indicate that they speak this language, "as well as their native one." Another $22.2 \%$ of respondents admit that they do not understand and speak well. This category of migrants had an age composition of 52+, some of them did not work anywhere, and those who worked in lowskilled jobs noted that their language skills were enough for them to communicate.

Thus, the situation of Chechen migrants, their selfdetermination in the new environment, identification preferences are contradictory in their manifestations. No less significant are the differences in gender selfidentification, which find their expression in the tangible difference in reactions, feelings and attitudes to specific parameters of their lives among men and women. To put it in general terms, the level of a more positive perception of reality in women is much higher than what men demonstrate, which means that it is women who have and realise a more significant adaptability potential. Among young people, during the interview, all respondents recognised the importance of the values of Islam in their lives and ideology. The concept of faith allows them to analyse the mechanisms of meaning-making in their lives, the place and significance of faith at turning points in their community's history, and confidently demonstrate their conviction in the constitutive role of religious meanings in social life. "There is no way without faith in Allah; everything that has happened to our people is a punishment for us for departing from his laws. It's easy for me to live with faith; it's like breathing. Everything depends on faith, life becomes clear, what is good and bad" (Islam - 21 y.o.). At the same time, young people demonstrate an understanding and tolerant attitude to their parents' calmer attitude to religion. "Well, parents, they grew up under the Communists, it was strict there, so they are not like us young people with faith. I have been keeping monthly sawm since I was 9 years old, and my parents don't always." (Zarema - 19 y.o.).

The young men's arguments about the constitutive role of religion in the context of family and marriage relations are interesting. "I can't live with a woman without nikah, it's haram, there are a lot of girls here, well, they cling, no, not ours, they are Belgians. They're bothering me; I can't touch them. Therefore, as soon as I go to work, I get married and want many children. This is sunnat."(Selim - 19 y.o.).
"A Muslim should get married in time, so that he would not be tempted and would not look at other people's women, this is a big haram, and when there is his wife, there is no need to look at others, so you need to get married. True, she should be beautiful but also smart; of course, it is difficult to get along here; the wife must be educated and able to work."(Sayd-Magomed - 20 y.o.).

- "It seems strange to the Belgians that we don't live separately from our parents, well, with some guy, they think we want to, but the parents don't allow it, they don't understand, well, that it's... indecent, well, before marriage, why is it necessary? Although if they do it that way, it's their business, it's not for us to judge" (Milana 19 y.o.).

- "In Islam, you can't live with a man before marriage, and nothing is allowed with him at all, but here in Belgium it's all the time, they already live at the age of 14 , well, what is modernity? I am categorically against this, and I think we are better and cleaner in this. This is a big haram; I'm even scared for them." (Liana - 21 y.o.).

According to the youth, faith for parents was a hereditary and sociocultural sign "Parents were believers, and their parents too, but how else, without faith, are we Chechens?" (Amina - 18 y.o.).

"I feel better when I pray. Somehow the soul brightens up or something? I ask the Almighty that he would stop me from confusion, well, that I would not get confused, that Shaitan would not lead me astray. The girls at school wanted me to smoke; I had a moment inside, but then I prayed for a long time, and the desire passed, and now I don't want to at all. And they can, they are infidels, they will burn in hell for this haram." (Elina - 18 y.o.)

"It's easy to live with faith, you know how to act in every case, you don't have to think long. Faith helps me even in my studies. I ask the Almighty for patience to learn; they ask a lot, it's not easy to learn, but it's easy for me, I succeed, I pray very much, but I don't condemn others; they have their answer in front of the Almighty."(Rasul - 17 y.o.).

We tried to identify sensitivity to extremist trends in Islam and attitude to this ideology's nature during the interview. As extremist-minded young people formalise their narrative in the conditions of migration.

-"They don't like us, anyway, Muslim migrants, well, they are treated worse than the same migrants, for example, Armenians. Therefore, such sentiments, well, some leave for Syria. It's not an option, but it's a protest, as it seems to me. Christians first stirred up everything, killed and pitted Muslims, and now we are terrorists." (Vakha -20 y.o.)

- "It seems to me that many people go to Syria because of some problems, in the family, for example. 
And those (recruiters - K.L.'s note), well, they know, they catch such moods through networks, and then there is a lot of injustice in the world, and only Islam can honestly regulate everything, and there is a lot of immoral here, they drink, drugs, it is not clear where the man is, where the woman is. in general, not the worst go there, do not think." Aslan (19 y.o.).

-"I think the girls are going to Syria, well, there are real guys there. Ready to die for religion, and they are very reliable, maybe that's why; I don't know? I wouldn't go there, but I think everyone has their understanding. And if the husband? She has to follow him; it's according to the Koran, so what kind of terrorist is she?"- (Elina 18 y.o.).

From the survey, it was possible to identify several clearly manifested positions:

- Muslim communities are perceived by the European environment as generally alien, having a different experience of socialisation, language and cultural capital, and young people feel this attitude for themselves;

- according to both the first and second generation of Chechen migrants, the most crucial adaptation factor is the search for mutual understanding with the host society. Aggression (hidden, open) on the part of the host party towards Muslims was noted in the interview. Some young people expressed doubt about the possibility of a significant part of the diaspora of prospects for financial growth with a high social status in European society, even if they accept several its values.

- "Even if we dissolve into them, they consider us second-rate, migrants, it's not easy for many to make a career here, there are a lot of hidden forces" (Sulim -19 y.o.).

But such reasoning was not dominant. In a significant part of the interview, both boys and girls agreed that "the opportunities in Belgium and Europe, in general, are tremendous, the main thing is that you have to prove that you can try your best to get out, no one bothers you to study here, just try (Maryam - 19 y.o.)

"Yes, it is quite possible to get a job here, all roads are open, just not everyone wants to work with studies, learn languages, a normal attitude towards migrants, just don't do stupid things yourself" (Sayd-Magomed - 20 y.o.).

In the context of cultural integration, according to respondents, the objective conditions of the migration environment narrow the field of choice of cultural strategies of the migrant and hinder the process of multiculturalism. The advantages of the European lifestyle available to migrants often become insufficient compensation for the gap with their native culture and language, so many adapt to the new environment based on building their authority within their ethnic community. "We are considered Europeans if we recognise gay parades and same-sex marriages; if it is alien to us, according to the Belgians, we are too undemocratic. I would like them to understand us, and we would not condemn them; they are at home, I think so" (Madina - 21 y.o.).

The second-generation respondents explained the positioning of their religious and cultural identity by the need to identify their belonging to a group clearly understood as a source of support in an aggressive environment. Religion for young people is perceived as a protective mechanism and a manifestation of their religious "self" so that "no one will say that I betray my faith." (Elina - 18 y.o.). Therefore, namaz, Ramadan and hijabs remain the main signs of Islamic identity among young people, although the variability of clothing for girls is allowed to certain limits, like the absence of a beard for young people. At the same time, the institution of the opinion of the ethnocommunity is so high among both generations that the boundary between where the subjective motivation and the inner attitude of the individual begins and how the individual's behaviour correlates with the value judgment of the community is not always realised. It is important to note that both generations pointed to the psychological severity of the personality of this addiction.

There is a specific hostile non-Muslim world in the minds of the young, and one of the tools to repel the aggressive world of "non-Muslims" was the idea that the necessary level of protection is provided only by the unification of all Muslim communities into a quasiunified ethnoreligious group based on the community of religion. The "circle of trust", according to young people (this idea was expressed exclusively by young men), is formed not on the principle of "one blood" but the doctrine of "one faith".

Despite the high importance of ethnic identity and dependence on the values of national culture (adats), the religious factor increasingly prevails in the rhetoric of the second generation of Chechens.

\subsection{The place of civic identity in the self- identity of two generations of migrants}

One of the critical points that have a political and ideological meaning is the place and degree of significance in the structure of self-identification of civic feelings that find their expression concerning the country of residence, the country of origin of the migrant or the historical homeland. The results of a survey of Chechen migrants in 2011 testified that Russian citizenship was not included in the core of identification preferences when constructing the general identity of a Chechen person and was located on its periphery. Only $8.0 \%$ of the interviewed Chechen migrants in Belgium indicated this side of their self-identification. 
Among the second generation, the attitude towards the small homeland is contradictory: on the one hand, there is a desire in the rhetoric to show that they are attached to their fatherland, proud of the glorious history of the past of Chechens, customs and traditions, go on vacation to the small homeland. On the other hand, a generalising narrative can be distinguished from the surveys: none young people expressed a desire to live in Chechnya. The picture of their parents about Chechnya was mythologised and did not coincide with their expectations. The complexity of the socio-political and legal situation in Chechnya strongly discourages young Chechens. Everyday social practices in Belgium with that guaranteed set of legal institutions seem to them significantly attractive, understandable and familiar. Distancing from the youth of Chechnya was expressed in terms of "they are different", "I don't understand a lot about them", "I am a stranger to them".

"It seems to me that there is a lot of show-off and hypocrisy here, people fawn over the bosses, the rich, bribes everywhere and no one is surprised at this. When I offered to complain, I was mockingly told that this was not Europe. And why do they tolerate it? They are to blame; they are cowards, I would not like to live here" (Sayd-Magomed - 20 y.o.).

"I go into a shop in the village, everyone looks at me, and then they discuss how I'm dressed and even my hairstyle; what's their business? No one cares about you in Belgium, as long as you follow the law. And they also pay many bribes for their studies, and then how to work? I was told that you could get a job in the same way. How can you live like this? And my mother told me something completely different in childhood about Chechnya" (Madina - 21 y.o.)

"In general, it seems to me that you can live in any part of the Earth if you know the language and have a job; what's the difference, there are good and bad people everywhere. It's the parents who want to go home, and we, well, of all my friends and acquaintances, no one wants to live in Chechnya now, well, there is no understanding of the law that you have your rights, it's just stuffy there. I would say so. No, I'm not going to live there permanently, on vacation, that's fine. You know, to be honest, parents don't really want to do that right now. Previously, everyone was crying, bored, and how often they began to drive, the mood is no longer the same."(Sayd-Magomed - 20 y.o.)

-"It's not easy for girls at home, I don't want to go there, and I don't want to live in Belgium, I want to go to England; I was there at a student conference, I liked it. And what about Chechnya, let my parents go when they get old, I don't want, with my ideas, no one will even take me there to get married" (laugh) (Madina - 21 y.o.)

-"I went to Chechnya with my parents twice. Once, I was still a little girl at 10 years old, and last year. The first time I liked it, but now I don't. There are some kind of duplicitous people there; they condemn someone all the time, they only talk about wealth all the time. I told my mom that I wouldn't set foot there again. My friend got married, lived for half a year - came back, couldn't stand it. My mother-in-law said that her languages would not be helpful to her; I need an au pair, in general, you know, our Chechen alignment. Although there are a lot of them here either, there is at least some choice, and there is darkness. It doesn't seem to me that this is my homeland for some reason. Yes, you can live anywhere; there is no difference as long as there are conditions, it seems to me so." (Leila - 21 y.o.).

During the survey in 2011, respondents stressed that they wanted to marry their daughters "at home" and want to marry their son to a bride from Chechnya. Probably, psychological homesickness and the desire to intuitively strengthen the connection with the motherland through the marriages of children still dominated, rather than the practical expediency of finding a bride or groom in the country of migration.

When interviewing young people in 2019, the emerging trend of getting married or marrying European Chechens was definite. This desire was explained not only by formal objective circumstances, such as their lack of problems with a residence permit, knowledge of the language, etc. The "mental closeness" with Chechens, who grew up in Europe, was emphasised. "Bringing a bride from home is very problematic. They don't even know the language and the conditions here; many believe that there are a lot of good girls here, and it's easier because there are a lot of problems with documents. Here the girls own the situation, well, it's easier with them in general." (Islam - 21 y.o.).

Analysing the data obtained, it is possible to identify the basis of self-identification of Chechen migrants (the older generation) in the form of a set of ranked value prescriptions and preferences that make up ethnic and social identity.

In the data set of a survey conducted in Belgium in 2011, the placement of accents presents the following picture: the value of "Being a decent, honest person" occupies a prominent dominant position here $-70.7 \%$ (male respondents $-72.7 \%$; female respondents $-69.2 \%$ ). The next most important position is "Being a good family man" - 61.3\% (male respondents - 72.7\%; female respondents - 69.2\%). The third most important place among respondents from Belgium is the value of "Being a religious person $-42.7 \%$ (male respondents $-42.7 \%$; female respondents $-43.6 \%$ ).

Paradoxically, it is an empirical fact that such a seemingly significant value for self-identification as "Being a qualified worker", among the first generation of Chechen migrants interviewed in Belgium in 2011, occupies one of the bottom lines in the significance rating 
$-38.2 \%$. It can be assumed that the low significance of this value among respondents of this period is explained by objective difficulties, namely: arrival in the country already in the middle of life, insufficient command of the title language, weak social skills, different standards of the basic educational systems of Russia and Europe.

\section{RESULTS}

The conceptual apparatus of modern sociology of migration has expanded the arsenal of possibilities in using tools in assessing the integral characteristics of a person's self-identification in the conditions of migration [9]. Therefore, it became possible to consider the dynamics of sociocultural value transformations of two generations of migrants and identify indicators that have a resource for potential adaptation of the entire ethnic community. As part of the sociological research, the author came to the following theoretical and practical conclusions:

- It is evident that the process of adaptation in Belgium for two generations (parents and their grown-up children) is complex, non-linear. At the same time, there are "problem zones" of adaptation; demographic strata differentiate their essential load in many indicators: parents have one set of problems, children have another.

- The dominant values and behavioural strategies of young Chechens have been identified, consisting in their acceptance of the fundamental democratic freedoms of the Western legal model while being aware of their ethnic identity. Among the new generation of young Chechens, there is a trend not to consider the sociocultural attitudes of their nation as a universal scale of axiological values.

- Cultural relativism is becoming part of the tolerant consciousness of young people. This process can be considered as a potential resource of adaptation in the conditions of migration.

- The socio-economic, cultural complexity of the adaptation of parents who came to Belgium in the middle of their lives determines their value and integration moods: the concept of "home" is associated with Chechnya, so in old age, they want to be at home. The second generation of migrants experience complex psychological feelings about the construct "home" as a system of values and a space of comfortable existence: they don't feel at home either in Belgium or in Chechnya. Considering Chechnya in terms of "Homeland", "Ancestral Land", almost all respondents admitted that they feel "strangers" there. The affection to the Chechnya of the first generation is emotionally nostalgic; there is a narrative from the life of the past youth, peaceful multinational Chechnya. Despite the feeling of anxiety and disappointment in assessing the current political situation in Chechnya, the common denominator for the sentiments of the Chechen migrants of the older generation is their mental desire to return to their historical homeland.

- To a large extent, the mythological image of Chechnya presented by parents in migration does not meet their expectations. They face a different picture in their historical homeland than their parents painted for them. The idea was expressed cautiously that there is no specific binding to any territory; this is a new sense of self, not characteristic of the first generation.

- Despite the high importance of ethnic identity and dependence on the values of national culture (adats), the religious factor increasingly prevails in the rhetoric of the second generation of Chechens.

- Anxiety about the blurring of ethnic identity in grown-up children, their "infection with liberal values" was clearly indicated in surveys among the older generation. They recognise their responsibility for the "costs" of raising their children in Belgium while adequately assessing the enormous potential of children in self-realisation in career growth and life aspirations in a prosperous, socially protected, European environment. Among the second generation of migrants, the opinion also prevails that the opportunities for social realisation in migration are pretty high. However, there are also costs in the arsenal of options due to the migrant status.

- Adult migrants have already established relatively unchanged value systems and corresponding patterns of behaviour. Due to closer and more frequent contacts with representatives of another culture and the instability of their value systems, their children's values often overlap with the values of the dominant culture [10]. But this axiological adaptation is selective and confirms the thesis of the "different acculturation strategies" of the individual [11]. Hence the generation gap becomes inevitable. But even the second generation of emigrants, as studies show, cannot yet be considered free from the influence of the ethnic culture of the country of exit.

A specific new model of identity is emerging among the second generation of young people, namely: they have a pronounced religious identity, but at the same time, national culture, language, customs and traditions do not lose their relevance. They are focused on the future; there is no binding to a specific territory, they do not feel a sacred meaning in their "native land" and "fatherland". They are pretty organically embedded in the liberal values that are significant to them while distancing themselves from the norms that stigmatise in the public consciousness of the Chechen community. A high degree of collective identity indicates individual freedom and autonomy of personal life. The second generation of migrants does not feel any kinship with the titular nation of residence or the youth living in the autochthonous territory. Some studies have designated this new identity model, which is just emerging, as "new Chechens" in some studies. This is exactly what young Chechen 
migrants in Norway called themselves in the survey. $(\mathrm{N}=220 / 5 \%)$. The question is, what are the contours of the possibilities of legitimising the new identity model and what are the prospects for its social adaptation in the migration conditions?

\section{CONCLUSION}

- Adaptation and transformation of values of parents and children of migrants who have been living in migration for more than 20 years have a different trajectory.

- the difficulty of parents' adaptation in the conditions of migration had a pronounced socio-economic character with a significant psychological burden of war trauma

- the complexity of the adaptation of the younger generation is shifting more into the plane of valuecultural problems with a strongly pronounced Islamic factor. At the same time, the process is caused by several specific features:

- on the one hand, it is the influence of values and models of social practices of parents who grew up in the conditions of the ideology of the Soviet system, but with a substantial share of the worldview of traditional ethnic culture, plus traumatisation by the war, which became the main reason for migration to Europe.

- on the other hand, the second generation of migrants are children who grew up within the values and norms of the Western model of civil society with its cult of personal freedom, the autonomy of subjectivity and inviolability of legal institutions;

- thirdly, the influence of ethnic and religious ethnocommunity as a social institution that continues to play a prominent role in a foreign country as an actor of collective responsibility of the individual;

- Fourth, both generations of migrants (parents who came to Belgium more than 20 years ago and their children born in Belgium or came with their parents as children) experience a sense of psychological discomfort that they are "not at home" either in Belgium or in Chechnya. This "permanent migrant syndrome" remains an essential part of the psychological trauma in the structure of the formed social identity of Chechen migrants of the first and second generations of migration.

\section{REFERENCES}

[1] L.U. Kurbanova, Problems and processes of gender self-identification of Chechens: theoretical and empirical research [Problemy i processy gendernoj samoidentifikacii chechencev: teoreticheskoe i empiricheskoe issledovanie] // Krasnodar, publishing house "Enlightenment - South" [Krasnodar, iz-vo «Prosveshchenie - Yug»], 2012, $303 \mathrm{p}$.
[2] Muslim Europe or Euro-Islam: politics, culture, and citizenship in the age / Ed. by Nezar AlSayyad, Manuel Castells, Plymouth, 2002, p. 19.

[3] D.L. Lobodanova., I.G. Starikov, Analysis of the main factors of adaptation of migrants in a foreign cultural environment [Analiz osnovnyh faktorov adaptacii migrantov $\mathrm{V}$ inokul'turnoj srede], Management Issues [Voprosy upravleniya] 6 (2016) 122-123. Retrieved from: https://cyberleninka.ru/article/n/analiz-osnovnyhfaktorov-adaptatsii-migrantov-v-inokulturnoysrede/viewer

[4] V.A. Yadov, On the dispositional regulation of social behaviour of the individual (Methodological problems of social psychology) [O dispozicionnoj regulyacii social'nogo povedeniya lichnosti (Metodologicheskie problemy social'noj psihologii)]. M., 1997, 213 p; T.V. Emelianenko, Methods of intercultural research of values, Sociology: methodology, methods, mathematical modelling, (Sociology: $4 \quad$ M) [Metody mezhkul'turnyh issledovanij cennostej, Sociologiya: metodologiya, metody, matematicheskoe modelirovanie (Sociologiya: 4 M)] 9 (1997) 32-54.

[5] P. Berger, T. Lukman, Social construction of reality. A treatise on the sociology of knowledge [Social'noe konstruirovanie real'nosti. Traktat po sociologii znaniya]? M., Medium, 1995, 323 p.

[6] H. Abels, Romanticism, Phenomenological Sociology and Qualitative Social Research [Romantika, fenomenologicheskaya sociologiya i kachestvennoe social'noe issledovanie], Journal of Sociology and Social Anthropology [Zhurnal sociologii i social'noj antropologii] 1 (1998) 126.

[7] S. Bochner? The social psychology of cross-cultural relation // Cultures in Contact: Studies in CrossCultural Interaction / Oxford, Pergamon, 1982.

[8] F. Fukuyama, Identity. The desire for recognition and the policy of rejection [Identichnost'. Stremlenie k priznaniyu i politika nepriyatiya], - M.: Alpina Publisher Publishing House, 2019, 250 p.

[9] A.A. Andryushko, Theoretical approaches to studying migrants' adaptation in the host society: foreign experience [Teoreticheskie podhody $\mathrm{k}$ izucheniyu adaptacii migrantov $\mathrm{v}$ prinimayushchem obshchestve: zarubezhnyj opyt], Bulletin of the Institute of Sociology [Vestnik Instituta Sociologii] 8(4) (2017) 47-48. DOI: http://dx.doi.org/10.19181/vis.2017.23.4.480

[10] K. Word, A. Kennedy, Changing sociocultural adaptation [Izmenenie sociokul'turnoj adaptacii], International Journal of Intercultural Relations 
[Mezhdunarodnyj zhurnal mezhkul'turnyj otnoshenij] 23(4) (1999) 659-671 DOI: https://doi.org/10.1016/S0147-1767(99)00014-0

[11] Z.H. Lepshokova, Strategies of adaptation of migrants and their psychological well-being (on the example of Moscow and the North Caucasus) [Strategii adaptacii migrantov $\mathrm{i}$ ih psihologicheskoe blagopoluchie (na primere Moskvy i Severnogo Kavkaza)], Gryphon, 2012, 175 p. 